\title{
A educação especial em propostas curriculares para a educação infantil
}

\author{
Ivone Martins de Oliveira \\ Universidade Federal do Espírito Santo \\ Anna Maria Lunardi Padilha \\ Universidade Metodista de Piracicaba \\ Maria Flavia Silveira Barbosa \\ Universidade Federal de Uberlândia
}

\section{Resumo}

Este texto discute a maneira como a educação especial se apresenta em propostas curriculares para a educação infantil de municípios de diferentes Estados brasileiros, além do Distrito Federal. Foram analisadas propostas pedagógicas e/ou orientações curriculares para a educação infantil de nove municípios e do Distrito Federal, sendo a maioria desses documentos publicizadas em sítios de secretarias de educação no mês de janeiro de 2010. O estudo aponta, entre outros aspectos, a presença de uma concepção idealizada de criança que não corresponde à criança concreta que compõe o público-alvo da educação especial e predomínio de uma abordagem pontual, fragmentada e desarticulada da educação especial.

Palavras-chave: Educação infantil. Currículo. Educação especial.

\section{Special education in curricular proposals for child's educational}

\section{Abstract}

The text discusses how special education is presented in curricular proposals regarding children's education of districts located in different Brazilian states, besides the Federal District. We analyzed pedagogical proposals and/or curricular orientations related to children's education of nine municipalities and the Federal District, the majority of these documents publicized in education departments websites in January of 2010. The study indicates, among other aspects, the presence of an idealized conception of a child that does not correspond to the concrete child that is part of the special education target audience and the predominance of a regulatory, fragmented and disarticulated approach of special education.

Keywords: Children's education. Curriculum. Special Education. 
A educação especial em propostas curriculares para a educação infantil

\section{Educación especial en propuestas curriculares para la educación infantil}

\section{Resumen}

En este trabajo se analiza cómo se presenta la educación especial en las propuestas curriculares para los municipios de educación infantil en los diferentes estados brasileños, además Distrito Federal. Se consideraron las propuestas pedagógicas y/o lineamientos curriculares para la educación de la primera infancia a partir de nueve ciudades y el Distrito Federal, la mayoría de estos documentos publicada en sitios de los departamentos de educación en enero de 2010. La encuesta muestra, entre otras cosas, la presencia de un diseño idealizado de un niño que no se corresponde con el niño real que hace parte del público objetivo de la educación especial y el predominio de un enfoque específico, fragmentado y inconexo de la educación especial.

Palabras clave: Educación Infantil. Currículo. Educación Especial.

\section{Introdução}

Oavanço na consolidação de uma proposta para a educação infantil 140 que reconheça a especificidade do trabalho pedagógico dirigido aos bebês e às crianças pequenas implica discutir questões referentes ao currículo nessa etapa da educação básica.

A partir de 1996, intensifica-se, no âmbito do Ministério da Educação, a produção de documentos com o objetivo de fornecer subsídios aos sistemas de ensino e às instituições de educação infantil para a implementação de práticas educativas que estejam em consonância tanto com o objetivo maior dessa etapa da educação básica, que é o desenvolvimento integral das crianças de zero a cinco anos, como com as funções indissociáveis de cuidar e educar.

Com características diferenciadas, os municípios vêm atendendo, de forma distinta, às orientações e determinações estabelecidas nos documentos oficiais, conforme indicam estudos da área.Como elementos que interferem nessas distinções, Nunes, Corsino e Didonet (2011) indicam as condições sociais e econômicas desiguais dos municípios brasileiros, que produzem diferenças: a) na capacidade de oferta de educação escolar nos diversos níveis de ensino; b) na possibilidade de atender à demanda de matrículas; c) na organização administrativa das unidades de educação infantil; d) na disponibilidade de equipamentos e recursos didáticos; e) na elaboração e 
implementação das propostas para a educação infantil; e f) na formação dos professores. Diferenciados são, também, os modos de atendimento ao que estabelece a legislação para as crianças que são público-alvo da educação especial.

Na política educacional implementada pelo Governo Federal, dirigida à pequena infância, também se destaca a criação de leis e programas, inseridos numa perspectiva de política de educação inclusiva, que visam a atender às diversas especificidades das crianças com algum tipo de comprometimento no desenvolvimento', matriculadas nas classes comuns das unidades de educação infantil.

As propostas pedagógicas e/ou orientações curriculares dos sistemas de ensino implicam a articulação entre as determinações estabelecidas nos documentos oficiais em nível nacional e o contexto histórico, político e cultural local, o que contribui para produzir um quadro distinto no que diz respeito às configurações curriculares de Municípios e Estados da Federação.

Fundamentando as ações, programas e orientações curriculares para a educação infantil de diferentes sistemas de ensino, encontram-se concepções de criança, de desenvolvimento e de educação especial, as quais nem sempre são apresentadas com nitidez nas propostas pedagógicas e/ou orientações curriculares. Além disso, nem sempre há sintonia entre as concepções anunciadas e as orientações curriculares, expressas nos documentos desses sistemas de ensino.

Diante disso, este texto discute a maneira como a educação especial se apresenta em propostas curriculares para a educação infantil de municípios de diferentes Estados brasileiros, além do Distrito Federal. Mais especificamente, busca identificar e analisar concepções de criança, de desenvolvimento e de educação especial, bem como práticas de atendimento às especificidades das crianças que são o público-alvo da educação especial, expressas em documentos oficiais de Secretarias de Educação de nove municípios brasileiros e do Distrito Federal.

Considerando, como Sacristán (2000, p. 107), que o "[...] currículo não pode ser entendido à margem do contexto no qual se configura e tampouco independentemente das condições em que se desenvolve [...]", inicialmente, apresentam-se breves apontamentos sobre o contexto histórico e político em que se desenvolvem as ações e propostas curriculares para a 
A educação especial em propostas curriculares para a educação infantil

educação infantil. Vale destacar as Diretrizes Curriculares Nacionais para a Educação Infantil (DCNEIs) e as principais orientações da política para a educação especial nas últimas décadas. Em seguida, apresentam-se algumas contribuições da perspectiva histórico-cultural para a compreensão dessa questão e, por fim, à luz do que foi apresentado, analisam-se concepções e práticas em propostas curriculares de municípios brasileiros.

\section{Educação infantil, criança e educação especial}

Desde a promulgação da Lei n 9.394, de 20 de dezembro de 1996, é possível identificar avanços significativos no aumento do número de matrículas e no estabelecimento de um ordenamento legal que orienta os sistemas de ensino na oferta de educação infantil. Se os documentos oficiais se baseiam em um discurso que defende os direitos fundamentais da criança à educação, o enfrentamento das desigualdades sociais e a promoção de maiores níveis de igualdade, ainda há que se percorrer um longo caminho até que esse discurso se concretize em um conjunto de ações que efetivamente promovam a igualdade de oportunidades educacionais para as crianças de zero a cinco anos.

142 Com o objetivo de orientar os sistemas de ensino sobre procedimentos para a implementação de uma educação infantil de qualidade, o Ministério da Educação (MEC) publicou, nos últimos anos, vários documentos, entre eles, as DCNEls aprovadas em 1999 pela Resolução CNE/CEB n 01, 7 de abril de 1999 e atualizadas em 2009 por meio da Resolução CNE/CEB n 05, de 17 de dezembro 2009.

Entende-se que as propostas pedagógicas e/ou orientações curriculares de municípios brasileiros se constituem em documentos interessantes para compreender a maneira como uma determinada Secretaria de Educação articula e sistematiza orientações oficiais em nível nacional, os modos de conceber a educação infantil e as condições concretas de uma determinada realidade, produzindo um documento que, embora contenha orientações que não necessariamente refletirão o modo de pensar da totalidade dos profissionais envolvidos com a educação infantil, nem suas práticas, será difundido como a perspectiva oficial num dado tempo e espaço².

Paralelamente às orientações curriculares e dando suporte a elas, as DCNEls difundem concepções de criança e desenvolvimento, de educação infantil, de currículo e de educação especial, as quais os diversos sistemas de 
ensino devem incorporar em suas orientações curriculares para a educação infantil.

A concepção de criança é um aspecto fortemente marcado nos estudos da área da educação infantil e também nos documentos oficiais. Discorrendo sobre a "nova base conceitual e jurídica" para a educação infantil, a partir da Constituição Federal de 1988, Nunes, Corsino e Didonet (2011) destacam a construção de uma nova visão sobre a criança que, nos documentos oficiais, começa a ser reconhecida como pessoa completa, ainda que em processo de formação, cidadã, sujeito de direitos que deve ser "prioridade absoluta" no âmbito da família, nas políticas estatais e na sociedade. Difunde-se, segundo Nunes, Corsino e Didonet (201 1, p. 38), uma concepção de criança como "[...] um sujeito histórico, social, produtor de cultura, ativo e criativo, cujo desenvolvimento se dá de forma indivisível [...]", criança que necessita, portanto, ser cuidada e educada na instituição de educação infantil.

Sobre a concepção de desenvolvimento infantil que fundamenta as DCNEls, é possível afirmar que há uma oscilação entre ideias de cunho naturalizante, que entendem o desenvolvimento como um processo espontâneo e natural a ser vivido/construído pela criança e apenas acompanhado pelos professores, e ideias que assumem o caráter histórico desse desenvolvimento e a importância da apropriação pelos pequenos do conhecimento humano elaborado historicamente. No art. $3^{\circ}$, por exemplo, lê-se:

[...] o currículo de Educação Infantil é concebido como um conjunto de práticas que buscam articular as experiências e os saberes das crianças com os conhecimentos que fazem parte do patrimônio cultural, artístico, ambiental, científico e tecnológico, de modo a promover o desenvolvimento integral das crianças de $\mathrm{O}$ a5 anos de idade (BRASIL, 2009).

Nessa definição, há uma preocupação em marcar o papel da instituição de educação infantil como espaço de articulação de diferentes conhecimentos e experiências, de desenvolvimento das crianças em suas diferentes esferas e, art. $8^{\circ}$, de "[...] direito à proteção, à saúde, à liberdade, à confiança, ao respeito, à dignidade, à brincadeira, à convivência e à interação com outras crianças" (BRASIL, 2009). Cuidado e educação são funções a ser implementadas por meio de uma prática pedagógica que se atualiza, assentada nas interações e na brincadeira. 
A educação especial em propostas curriculares para a educação infantil

As propostas curriculares para a educação infantil devem contemplar, também, as especificidades culturais, étnico-raciais e de localização das crianças e de suas famílias em territórios urbanos ou do campo, bem como das crianças com deficiência, transtornos globais do desenvolvimento ou altas habilidades e superdotação.

Oenfoque às crianças de zero a cinco anos que constituem o público-alvo da educação especial nessas Diretrizes é imprescindível, considerando a crescente demanda nessa etapa da educação básica, bem como os documentos oficiais que determinam 0 atendimento às especificidades desses sujeitos (BRASIL, 2001; 2008). No que diz respeito às crianças atendidas pela educação especial, dados do Censo Escolar MEC/INEP/2013 indicam que, nesse período, havia, na educação infantil, "[...] 17.648 matrículas em creches, sendo 10.522 no ensino regular $(59,6 \%)$ e 7.126 em escolas e classes especiais $(40,4 \%)$. Na pré-escola, são 42.311 matrículas, sendo 32.460 no ensino regular $(76,7 \%)$ e 9.851 em classes e escolas especiais $(30,3 \%)^{\prime \prime}$ (BRASIL, 2014, p. 3).

Desde 2001, com a aprovação da Resolução CNE/CEB n² 2, de 11 de setembro de 2001, que institui as Diretrizes Nacionais para a Educação 144 Especial na Educação Básica, intensificou-se a responsabilidade da escola regular pela matrícula de sujeitos com deficiência, ainda que essa Resolução indicasse a possibilidade de a educação especial substituir os serviços educacionais comuns. Define o documento que esse atendimento pode ser efetivado tanto nas salas comuns, com a atuação do professor da educação especial e outros profissionais de acordo com as necessidades dos alunos, como em salas de recursos, com atividades de complementação ou suplementação curricular.

Para a educação infantil, no Parecer CNE/CEB nº 17, de 3 de julho de 2001, que trata das Diretrizes Nacionais para a Educação Especial, é ressaltada a "[...] identificação das necessidades educacionais especiais e a estimulação do desenvolvimento integral do aluno, bem como a intervenção para atenuar possibilidades de atraso no desenvolvimento" (BRASIL, 2001, p. 56). Essas diretrizes determinam que o currículo a ser desenvolvido com as crianças na educação infantil é aquele definido pelas Diretrizes Curriculares Nacionais para a Educação Infantil. Considerando as necessidades especiais das crianças, esse currículo pode sofrer adaptações "graduais" e "progressivas", por meio de atividades, recursos ou técnicas específicos. 
Possibilitando um passo importante de forma a alterar, no ordenamento legal, o modo de ver a deficiência e a educação da pessoa com deficiência na escola regular, em 2009, foi publicado o Decreto n 6.949, que promulga a Convenção Internacional sobre os Direitos da Pessoa com Deficiência e seu Protocolo Facultativo, assinado em New York, em março de 2007. No que diz respeito à educação de pessoas com deficiência, o Decreto determina, no art. 24, que os Estados-Partes assegurarão a efetivação de um sistema educacional inclusivo em todos os níveis de ensino e garantirão que as "[...] pessoas com deficiência não sejam excluídas do sistema educacional geral sob a alegação de deficiência e que as crianças com deficiência não sejam excluídas do ensino primário gratuito e compulsório ou do ensino secundário, sob a alegação de deficiência" (BRASIL, 2009).

Diante disso, em 2008, o Ministério da Educação instituiu a Política Nacional de Educação Especial na Perspectiva da Educação Inclusiva, que se constitui num dispositivo legal importante de forma a configurar a educação especial como uma modalidade complementar e suplementar ao ensino comum e não mais com a possibilidade de ser substitutiva. Nesse documento, uma atenção especial é destinada ao Atendimento Educacional Especializado (AEE), que tem como função "[...] identificar, elaborar e organizar recursos pedagógicos e de acessibilidade que eliminem as barreiras para a plena participação dos alunos, considerando suas necessidades específicas" (BRASIL, 2008 , p. 10). O AEE tem uma proposta educativa diferenciada daquela desenvolvida com a criança na sala de aula comum e deve ocorrer em horário contrário ao das aulas ${ }^{3}$.

Ao tratar da educação especial na educação infantil, Garcia e Lopez (201 1) e Cotonhoto (2014) destacam alguns desafios na implementação de uma educação especial que leve em conta as especificidades dessa etapa da educação básica. Garcia e Lopez chamam a atenção para a existência de um único modelo de atendimento educacional especializado para toda a educação básica. Ao lado de desafios decorrentes da própria compreensão do que seja o currículo na educação infantil, Cotonhoto (2014) indica outros que se referem à educação especial numa perspectiva inclusiva: a articulação entre os diferentes profissionais que atuam com as crianças com deficiência, transtornos globais do desenvolvimento e altas habilidades e superdotação; a necessidade de se ter um professor especializado para auxiliar o professor regente no que concerne às estratégias didáticas adotadas; o aprofundamento 
da discussão do que significa um trabalho "suplementar" e "complementar" no AEE; a necessidade de investimento em programas de formação continuada que efetivamente forneçam subsídios aos profissionais para atuar com as crianças que são público-alvo da educação especial.

Reportando-se às DCNEls, foi identificada uma única passagem que remete, especificamente, às crianças que são o público-alvo da educação especial. $\bigcirc$ art. $8^{\circ}, \S 1^{\circ}, \mathrm{VII}$ determina que as propostas pedagógicas da educação infantil devem criar condições para a "[...] acessibilidade de espaços, materiais, objetos, brinquedos e instruções para as crianças com deficiência, transtornos globais do desenvolvimento e altas habilidades/superdotação" (BRASIL, 2009). Observa-se que, no único momento em que há uma referência explícita à educação especial, nesse documento, o que se destaca é a acessibilidade 4 .

Nesse contexto, que inegavelmente apresenta avanços para o atendimento às crianças de zero a cinco anos, mas que são limitados, considerando as demandas, o texto em questão se propõe a discutir sobre a educação especial em propostas pedagógicas para a educação infantil, elaboradas por Secretarias de Educação, para orientar a prática educativa nas unidades de

146 educação infantil, enfocando, sobretudo, as concepções de criança, de desenvolvimento e de educação especial que sobressaem nesses documentos, bem como as principais ações propostas para o trabalho com as crianças que são o público-alvo da educação especial.

Antes, porém, de apresentar os dados obtidos nesses documentos e as análises acerca deles, é importante explicitar o referencial teórico a partir do qual procedem as referidas análises.

\section{Educação infantil e educação especial: uma abordagem histórico- cultural}

A discussão sobre como a educação especial se apresenta nas propostas curriculares de educação infantil traz para o debate concepções de infância e de desenvolvimento infantil que compõem os fundamentos conceituais e metodológicos das práticas pedagógicas, desenvolvidas nessa etapa da educação básica. 
Assumem-se, neste texto, as formulações da perspectiva histórico-cultural de Lev Semenovitch Vigotsky (1997; 2000) cujos estudos possibilitam entender como a educação infantil pode, hoje, cumprir seu papel: inserir as crianças no mundo da cultura, além de satisfazer suas necessidades básicas e protegê-las. Tal perspectiva articula-se com as ideias de Dermeval Saviani (2003) acerca do papel da educação na formação do homem.

Vigotsky (2000) destaca que o caminho que leva a criança da esfera biológica do desenvolvimento à esfera cultural, simbólica é determinado pelo outro: pela linguagem e pela significação que o outro atribui à criança e aos objetos e fenômenos do mundo para a criança.

Assim, o desenvolvimento infantil, na perspectiva assumida, é entendido como um processo de caráter histórico e dialético, que depende do lugar que a criança ocupa na vida social, das relações que estabelece com os outros, seus parceiros sociais, ao longo de sua constituição como indivíduo humano. Essas proposições trazem repercussões importantes para a prática pedagógica na educação infantil. Pasqualini afirma que,

[...] em uma perspectiva histórico-cultural e histórico-crítica, a finalidade da educação escolar na primeira infância e idade pré-escolar é transmitir a toda e cada criança o patrimônio cultural do gênero humano, tendo em vista a promoção de seu desenvolvimento humano nas máximas possibilidades colocadas para cada faixa etária (PASQUALINI, 2012, p. 77).

Nesse sentido, não seria diferente a abordagem para prática educativa destinada a crianças pequenas com algum tipo de comprometimento em seu desenvolvimento biológico. Em que pesem os ritmos peculiares de desenvolvimento nas diferentes formas de deficiência e transtornos globais do desenvolvimento, o objetivo primordial da educação infantil é a apropriação pela criança dos instrumentos - materiais e simbólicos - elaborados pela humanidade, ao longo dos tempos; ou seja, o foco deve ser o seu desenvolvimento cultural, da mesma forma que o é para a educação de crianças sem deficiência. Os limites postos pela biologia não devem determinar limitações ao desenvolvimento cultural de todas as crianças. Nesse sentido, Vygotsky (1997, p. 82) afirma que as deficiências serão vencidas, primeiramente, em âmbito social, e que haverá um tempo em que a pedagogia se envergonhará do conceito de "criança deficiente". Em suas palavras, "[...] está em nossas 
A educação especial em propostas curriculares para a educação infantil

mãos fazer com que a criança cega, surda ou débil mental não seja deficiente. Então, desaparecerá também esse conceito, signo inequívoco de nosso próprio defeito" 5 .

Parafraseando Marx, Vigotsky (1997, p. 179) afirma, em sua obra Fundamentos de Defectologia: "[...] nossa existência social determina nossa consciência $[\ldots]^{\prime \prime}$. E mais, é propositivo quando enfatiza que a educação de qualquer pessoa, deficiente ou não, precisa ter metas e objetivos iguais - e isso é denominado de visão prospectiva da perspectiva histórico-cultural do desenvolvimento humano e vale para todos os que estão apartados pela violência da chamada exclusão social ou escolar.

Após expor, brevemente, as bases conceituais que orientam o nosso olhar para a criança, seu desenvolvimento, a educação infantil, bem como a educação especial no universo da infância, possa-se a apresentar a metodologia do estudo realizado.

\section{O percurso metodológico}

A metodologia selecionada para levar a efeito este estudo foi a aná148 lise documental, que incidiu sobre propostas pedagógicas ou outros tipos de orientações curriculares para os profissionais da educação infantil de nove municípios brasileiros, além do Distrito Federal7. $\bigcirc$ critério de escolha dos municípios foi seu destaque político e administrativo, servindo de referência para outros municípios. $O$ acesso à maioria dos documentos foi feito por meio de informações disponibilizadas em sítios de Secretarias de Educação desses municípios na internet, no mês de janeiro de $2010^{8}$.

Na tabela a seguir, são apresentadas algumas informações básicas sobre as propostas pedagógicas ou orientações curriculares selecionadas. 


\section{Tabela 1}

\section{Dados sobre os municípios a que pertencem as propostas estudadas}

\begin{tabular}{c|c|c|c|c|c|c}
\multirow{2}{*}{ Município } & \multirow{2}{*}{ Habitantes* } & \multicolumn{2}{|l|}{ Matrículas Creche** } & \multicolumn{2}{|c|}{$\begin{array}{c}\text { Matrículas } \\
\text { Pré-escola** }\end{array}$} & $\begin{array}{c}\text { Matrículas Ed. } \\
\text { Esp.Creche/ } \\
\text { Pré }\end{array}$ \\
\cline { 3 - 6 } & & Públicas & Privadas & Públicas & Privadas & \\
\hline 1 & 11.253 .503 & 60.690 & 200.983 & 180.683 & 76.431 & 3.060 \\
\hline 2 & 6.320 .446 & 46.464 & 52.228 & 71.804 & 55.546 & 1.314 \\
\hline 3 & 2.675 .656 & 4.550 & 9.758 & 12.704 & 29.726 & 315 \\
\hline 4 & 2.570 .160 & 1.534 & 21.538 & 29.721 & 26.063 & 1.331 \\
\hline 5 & 2.375 .151 & 6.061 & 26.234 & 15.587 & 29.579 & 755 \\
\hline 6 & 1.751 .907 & 20.804 & 13.070 & 11.067 & 15.914 & 817 \\
\hline 7 & 814.230 & 10.760 & 2.188 & 13.504 & 8.807 & 204 \\
\hline 8 & 803.739 & 3.736 & 3.997 & 6.712 & 11.552 & 166 \\
\hline 9 & 421.240 & 5.331 & 2.961 & 5.846 & 3.988 & 170 \\
\hline 10 & 327.801 & 9.854 & 1.097 & 7.736 & 1.398 & 174
\end{tabular}

Fonte | Elaborada pelas autoras

Nota $\left(^{*}\right)$ | IBGE/Cidades (2013)

Nota (**) | INEP (2012). Resultados finais do censo escolar

É possível constatar que há uma diferença significativa no número de habitantes e taxas de matrículas na educação infantil - e, nessa etapa da educação básica, nas matrículas inseridas na educação especial - nos diferentes municípios onde essas propostas foram elaboradas, o que leva a indagar sobre os reflexos dessas diferenças na elaboração e implementação das orientações curriculares desses municípios.

ano de finalização da Proposta 10 (2006) e da Proposta 5 (2013) indicado nos respectivos documentos aponta que há variações significativas também quanto ao período de elaboração das propostas selecionadas, considerando os documentos legais produzidos nesse intervalo de tempo, como as Diretrizes Curriculares Nacionais para a Educação Infantil, de 2009, e a Política Nacional de Educação Especial na Perspectiva da Educação Inclusiva, de 2008. 
A educação especial em propostas curriculares para a educação infantil

\section{Tabela 2}

Levantamento dos documentos para a educação infantil nos municípios estudados

\begin{tabular}{c|c|c|c} 
Propostas & Ano de publicação & $\begin{array}{c}\text { Quantidade de textos } \\
\text { consultados }\end{array}$ & $\begin{array}{c}\text { Número total de } \\
\text { páginas }\end{array}$ \\
\hline 1 & 2007 & 1 & 152 \\
\hline 2 & $2010-2011$ & 2 & 126 \\
\hline $3^{*}$ & Sem data $^{9}$ & 1 & 65 \\
\hline 4 & Sem data $^{10}$ & 1 & 148 \\
\hline 5 & 2013 & 1 & 126 \\
\hline 6 & 2009 a 2011 & 9 & 638 \\
\hline 7 & 2008 & 1 & 124 \\
\hline 8 & 2008 & 1 & 78 \\
\hline 9 & 2012 & 1 & 189. \\
\hline 10 & 2006 & 1 & 103.
\end{tabular}

Fonte | Elaborada pelas autoras. Sítios das Secretarias de Educação na internet

Nota $\left(^{*}\right)$ | Diretrizes Pedagógicas elaboradas para educação infantil, ensino fundamental e 150 EJA em um único documento

De modo geral, o conteúdo dos documentos analisados divide-se em: uma parte introdutória, em que se apresentam informações sobre o processo de elaboração do documento, dados históricos sobre a educação infantil no País, no município e no Distrito Federal; apontamentos sobre os princípios nos quais a proposta se baseia; âmbitos de experiências ou aprendizagens que podem ser propiciadas às crianças, com foco nas interações e na construção da identidade, em diferentes linguagens, no conhecimento do meio físico e social e no conhecimento matemático. A maior parte das orientações curriculares é composta por um texto único produzido por gestores de Secretarias de Educação, podendo ter a colaboração de professores da rede e/ou de um assessor externo. Em alguns casos, a proposta conta com textos de pesquisadores da área, como a Proposta 9. 
Na análise das orientações curriculares aos educadores, constata-se que, das dez propostas selecionadas, seis incluem um item em seus textos e/ou um caderno das orientações curriculares em que discutem a educação especial ou o atendimento às crianças indicadas à educação especial na educação infantil (Proposta 1, Proposta 3, Proposta 4, Proposta 5, Proposta 6 e Proposta 10|; enquanto as outras quatro fazem menções esporádicas e pontuais a essas crianças e às especificidades de seu cuidado e educação (Proposta 2, Proposta 7, Proposta 8 e Proposta 91 ${ }^{1}$.

Tendo como base os objetivos deste trabalho, é válido ressaltar, para a discussão sobre a educação especial nas propostas pedagógicas ou curriculares dos municípios, os seguintes aspectos: as concepções de criança, de desenvolvimento e de educação especial que sobressaem nessas recomendações e as principais orientações didáticas contidas nesses documentos para o trabalho educativo com essas crianças.

Essa discussão tem início com a abordagem das concepções de criança, de desenvolvimento e de educação especial que se destacam nas orientações curriculares dos municípios. É possível constatar que parte significativa das propostas faz menção a uma concepção de criança como "sujeito histórico e social", situado no tempo e no espaço, membro de um determinado grupo social, de uma cultura, de uma etnia.

Porém, na abordagem de características de bebês e crianças pequenas, das diversas linguagens e das orientações didáticas, convém ressaltar, ainda, em parte das propostas analisadas, uma visão de criança idealizada, deslocada de um determinado contexto histórico e cultural, seguindo os mesmos padrões e ritmos de desenvolvimento. Isso é observado, sobretudo, em algumas propostas em que há menções esporádicas à educação especial, como a Proposta 3, Proposta 7, Proposta 8 e Proposta 9.

estudo de Oliveira (2011) acerca da criança com deficiência na história das políticas educacionais brasileiras traz elementos importantes para a compreensão dessa situação. A autora aponta uma história de ocultamento e de silenciamento dessa criança no transcorrer de séculos de educação escolar no Brasil. Trata-se de uma criança que, durante muito tempo, não foi objeto de investimento social e político, em grande parte pelo fato de a deficiência estar 
A educação especial em propostas curriculares para a educação infantil

associada "[...] à improdutividade e à incapacidade de aprendizagem, de elaboração intelectual e intervenção sobre a realidade. Uma eterna infância!" (OLIVEIRA, 2011 , p. 5). Considerando esse lugar historicamente destinado à criança com deficiência, inseri-la em propostas pedagógicas, seja para a educação infantil seja para o ensino fundamental, constitui um grande desafio.

Por outro lado, na atualidade, quando se toma a criança como referência para a instituição de práticas educativas na educação infantil, podem surgir alguns equívocos. Ao analisar a tendência de algumas orientações curriculares de municípios catarinenses, Wiggers (2009) chama a atenção para os perigos de se tomar como referência uma visão "mítica" de criança - caracterizada por uma capacidade de "autogerir-se" - e de suas repercussões no trabalho do professor e nos conteúdos a serem abordados, delineando uma prática educativa espontaneísta.

Concernente à concepção de criança que se revela nas propostas curriculares analisadas, a ideia de ser histórico e social, é interessante notar que a historicidade proclamada - o que também é observado nos documentos oficiais - não ultrapassa a ideia de que existiram, ao longo da história humana, e existem, ainda hoje, diversas maneiras de compreender e tratar a

152 criança, com ou sem deficiência, e que diferentes grupos sociais, em distintos momentos históricos, entendem diferentemente a criança, seu desenvolvimento, sua educação, seu lugar na sociedade.

Não assumir - conscientemente ou não - um sentido mais abrangente do que seja a historicidade no desenvolvimento da criança leva à idealização da infância e a práticas espontaneístas no trabalho pedagógico na educação infantil. Ao contrário disso, considera-se primordial que as orientações curriculares para a educação infantil de um dado município ou instituição educativa para crianças de zero a cinco anos se fundamentem em uma perspectiva teórica que entenda o desenvolvimento humano, além do substrato biológico - quer seja esse substrato com limitações, quer não -, como a apropriação da cultura. Essa apropriação é sinônimo de processo educativo, que ocorre sempre de forma mediada pelo outro, pelos instrumentos e pelos signos.

Nas propostas analisadas, quando são abordados aspectos do desenvolvimento infantil ou características apresentadas por crianças de zero a cinco anos, raramente são feitas referências às peculiaridades do desenvolvimento de crianças com deficiência. Um exemplo a ser destacado é o modo 
como a brincadeira é abordada nessas propostas: embora o brincar seja tratado como um meio de expressão da criança e uma atividade essencial para suas aprendizagens, nas propostas analisadas, não se constatam referências à maneira como a brincadeira é vivenciada por crianças que são público-alvo da educação especial; não se problematiza tampouco se discute acerca do modo como a brincadeira se desenvolve nessas crianças nem sobre as práticas educativas que favorecem esse desenvolvimento.

A psicologia histórico-cultural ajuda a compreender que o desenvolvimento das crianças bem pequenas deve ser olhado pela perspectiva da atividade social que constitui as condições históricas concretas nas quais as crianças estão inseridas e das quais participam. Considerar que o desenvolvimento psíquico é histórico e depende da organização social do entorno da criança - com ou sem deficiência -, implica que, em uma proposta curricular, se dê ênfase ao contexto social e cultural em que essa criança está inserida, às formas de mediação pedagógica estabelecidas entre ela e esse contexto, aos elementos da cultura que favorecem o desenvolvimento do máximo de suas possibilidades e os quais devem ser apropriados por ela.

Dessa perspectiva, e no caso das crianças com deficiência e transtornos globais do desenvolvimento, sobreleva o papel dos processos (educativos) de apropriação cultural. Para Vigotsky (1997, p. 82, grifos nossos), "[...] a cegueira em si não faz a criança deficiente, não é uma defectividade, quer dizer, uma deficiência, uma carência, uma enfermidade. Chega a sê-lo somente em certas condições sociais de existência do cego" ${ }^{\prime 2}$. Como foi dito, em suas reflexões, o autor afirma que a deficiência deve ser vencida socialmente. Se o desenvolvimento humano é cultural, então, também a deficiência é cultural - uma vez que não é (só) biológica. A deficiência está no modo de organização da sociedade que não provê a todos os indivíduos - deficientes ou não - condições plenas de desenvolvimento. A limitação deixa de ser apenas do indivíduo, é pertinente a toda a sociedade: pais, professores, gestores, governantes etc.

Com base em uma perspectiva histórico-cultural do desenvolvimento, evidencia-se que a eleição de estratégias pedagógicas promotoras do desenvolvimento das crianças deve estar ancorada em proposições teóricas cuja centralidade está no papel mediador do outro, adulto e professor das crianças. $\bigcirc$ desenvolvimento, nessa perspectiva, é a superação dos limites 
condicionantes do orgânico, ou seja, a superação dos processos elementares do desenvolvimento do humano.

Um documento que se distancia um pouco dos outros ao tratar da criança da educação especial é a Proposta 5, que apresenta uma discussão mais consistente sobre a criança com deficiência e $\mathrm{O}$ atendimento às suas necessidades. Essas orientações curriculares apontam que um dos grandes desafios da educação infantil é a "valorização", "acolhimento" e "promoção da diversidade humana", manifestados por meio de componentes como a etnia, o gênero, o sexo, as deficiências físicas ou intelectuais e a classe social. $\bigcirc$ destaque às diferentes características das crianças está presente na fundamentação teórica da proposta, na discussão sobre a organização da educação infantil por ciclos, na concepção de infância, na defesa do olhar atento à criança concreta que adentra a instituição e na acessibilidade de materiais e brinquedos. $O$ texto chama a atenção para a necessidade de se ter um olhar "aberto às diferenças" e de se conhecer a criança da educação infantil, considerando seu contexto sociocultural, suas peculiaridades físicas e sensoriais e suas características étnicas. Nesse contexto, a concepção de criança com deficiência que emerge no documento vai além de uma visão 154 restrita e estática da criança e da deficiência; a proposta ressalta que a deficiência é apenas uma das faces dessa criança e essa é muito mais do que sua deficiência, que tem suas características modificadas no transcorrer do tempo devido às intervenções educativas a que é submetida.

Por outro lado, ao enfocar a educação especial, percebe-se algumas nuanças que distinguem as propostas, as quais podem ser observadas a partir de diferentes aspectos, como os conceitos-chave destacados. Termos como "diversidade", "educação inclusiva" e "acessibilidade" perpassam a discussão acerca do tema, indicando ênfases diferenciadas na abordagem das especificidades da educação especial, como pode ser observado a seguir:

a) Diversidade: as Propostas 3, 4 e 5 dão destaque à "diversidade". Nas orientações da Proposta 4, a diversidade é apresentada como um dos eixos do currículo e há a defesa de que a escola deve ser um espaço acessível para os educandos da educação especial, o que se efetiva, sobretudo, por meio de uma prática educativa que "respeite as diversidades" e promova a "socialização" e o "desenvolvimento da identidade" das crianças. Embora tenham sido identificadas, no que tange aos conceitos abordados, aproximações com as orientações curriculares em nível nacional, um aspecto a ser destacado é que, 
em alguns casos, a especificidade da educação especial parece se diluir em meio à discussão da diversidade cultural, étnica, religiosa e de gênero, como no caso das Propostas 3 e 5 .

b) Educação inclusiva e acessibilidade: as Propostas 1, 4, e 10 apontam uma ênfase maior a questões específicas da educação especial. Apesar de ter sido elaborada em 2006, a Proposta 10 chama a atenção para alguns temas que aparecem com mais frequência em documentos oficiais mais recentes, como a acessibilidade e formas de organização dos serviços de apoio nas unidades de educação infantil para atender às especificidades das crianças. Em consonância com os estudos de Garcia (2008), que indicam uma tendência de aproximação do conceito de inclusão ao de acessibilidade, na Proposta 4, este último é destacado no momento em que se apresentam orientações acerca de adequações de acesso ao currículo e sugestões para tanto, enfatizando principalmente os recursos para esse acesso por estudantes com diferentes tipos de deficiência, transtornos globais do desenvolvimento e altas habilidades e superdotação.

No que diz respeito à articulação entre as orientações contidas nas propostas e as determinações dos documentos oficiais, identifica-se certo descompasso.

Tomando como referência a Política Nacional de Educação Especial na Perspectiva da Educação Inclusiva (BRASIL, 2008), constata-se que, mesmo em propostas pedagógicas concluídas após 2008, há poucas referências à legislação mais recente na área. Para as propostas elaboradas a partir de 2008, também não há orientações a respeito do modo de organização da sala de recursos e do Atendimento Educacional Especializado ou de outros espaços e serviços destinados às crianças com deficiência, transtornos globais do desenvolvimento e altas habilidades e superdotação.

Nos diagnósticos e desafios apresentados nos documentos analisados, também sobressai a ausência de referências às políticas articuladas que envolvam diferentes setores, como educação, saúde e assistência social, bem como entre instâncias, federal, estaduais e municipais. $\bigcirc$ descompasso é observado, ainda, na proposta de organização do trabalho pedagógico no interior da própria unidade de educação infantil para atender às especificidades educacionais das crianças público-alvo da educação especial. 
A educação especial em propostas curriculares para a educação infantil

Diante desses descompassos, questiona-se sobre o real compromisso, por parte dos órgãos governamentais, em subsidiar a inclusão e permanência de todas as crianças - pequenas e grandes, com e sem deficiência - nas escolas comuns. Estudos realizados por Caiado e Laplane (2009) indicam que tem havido alguns avanços na política de inclusão escolar implementada pelo Governo Federal, entretanto esses avanços estão longe de atender às demandas colocadas por uma educação efetivamente para todos. $\bigcirc$ descompasso entre ações, desenvolvidas por diferentes instâncias governamentais, dificulta a implantação de políticas articuladas e o próprio trabalho educativo na unidade de educação infantil. Assim, o atendimento às crianças pequenas ainda é precário e não contempla as suas necessidades educativas.

$\bigcirc$ último aspecto a ser discutido na análise em curso se refere às proposições curriculares desses municípios para o trabalho educativo com crianças que são público-alvo da educação especial.

Observa-se que, em momentos em que se trata das experiências, conhecimentos e habilidades a serem abordados na prática educativa, bem como das orientações didáticas e de avaliação, poucas referências são feitas às singularidades dessas crianças. A análise das propostas pedagógicas 156 indica que, em sua composição, predomina uma abordagem genérica, fragmentada e desarticulada da educação especial, a qual, na maioria dos casos, se restringe ao âmbito dos princípios básicos, pouco sendo retomada nas passagens em que as propostas pedagógicas tratam de conhecimentos, saberes e experiências a serem disponibilizados para as crianças ou ao abordar orientações didáticas e avaliação. A articulação entre as atividades do atendimento educacional especializado e do ensino comum - conforme aponta a Política Nacional de Educação Especial na Perspectiva da Educação Inclusiva (BRASIL, 2008) - raramente é mencionada nas propostas analisadas.

Alguns documentos apresentam orientações gerais acerca do trabalho a ser efetivado, embora em momentos pontuais. Pode-se destacar a Proposta 10, que aponta alguns desafios que o sistema de ensino enfrenta ao implementar uma proposta de educação inclusiva. Problematiza aspectos desse contexto desafiante e indica a necessidade de algumas ações primordiais a serem desenvolvidas pela instituição de educação infantil e/ou Secretaria de Educação, como: promoção de infraestrutura e acessibilidade para crianças e adultos nas instituições de educação infantil; disponibilização de equipamentos e recursos especiais para o trabalho educativo; organização de serviços 
de apoio para atender às especificidades das crianças; maior articulação do trabalho desenvolvido pelos diversos profissionais da instituição; orientação às famílias quanto às características e necessidades especiais das crianças e formação dos profissionais.

Outros documentos, como a Proposta 1 e a Proposta 4, apresentam orientações mais detalhadas, sob a forma de listagem de recomendações para os professores.

As orientações curriculares da Proposta 1 chamam a atenção para a necessidade de o professor acreditar nas possibilidades de desenvolvimento dessa criança e envolvê-la no planejamento, ficando atento: à estruturação adequada dos ambientes e disponibilização de móveis, materiais e recursos adaptados, quando necessário; à organização das rotinas diárias, das atividades e dos tempos de forma a atender às possibilidades e potencialidades dessas crianças; à promoção de situações que estimulem a criança a se envolver e participar da dinâmica interativa da turma, expressar-se por meio de diferentes linguagens e cuidar de si; à necessidade de enfocar, na avaliação, suas capacidades e habilidades e não suas limitações.

Nas orientações curriculares da Proposta 4 há uma preocupação em detalhar algumas sugestões de ações que visem ao acesso ao currículo por parte das crianças. A proposta chama a atenção para a necessidade de adequações de acesso ao currículo e de elementos curriculares, tomando como referência as potencialidades dos educandos, e discorre sobre a avaliação. Discute, de forma mais detalhada, sugestões gerais de procedimentos que favorecem o acesso do educando ao currículo e aponta alguns procedimentos específicos para diferentes tipos de deficiência. Um aspecto a ser destacado nessa proposta é a recomendação de elaboração de um "plano pedagógico de atendimento individual" para o aluno da educação especial, o qual deve ser previsto no Projeto Político-Pedagógico da instituição e no currículo da sala de aula e contar com o envolvimento de todos os profissionais.

A Proposta 6 se diferencia das demais no que diz respeito ao espaço destinado a essa discussão: um caderno específico, com cerca de 80 páginas, para tratar de questões referentes ao atendimento às crianças que são o público-alvo da educação especial. $\bigcirc$ caderno integra relatos de experiências de educadores/professores que atuaram com crianças com deficiência no município. Os relatos foram produzidos como parte das atividades de um 
curso de formação continuada no segundo semestre de 2005. Inicialmente, o texto tece algumas considerações gerais sobre: a criança com deficiência, as adaptações necessárias ao trabalho educativo dirigido a essas crianças na unidade de educação infantil, o atendimento especializado e a atuação dos educadores. Em seguida, apresenta diversos relatos de experiências desses educadores, cujo foco é a prática educativa direcionada às crianças com deficiência física, visual, auditiva, intelectual e múltipla.

Um aspecto relevante a destacar, nessa proposta, é a participação dos professores, que trazem seus relatos e impressões sobre a prática educativa e as demandas colocadas pela educação especial. A perspectiva de "socializar fazeres" indica valorização do trabalho dos educadores e é uma prática encontrada em outros cadernos que compõem as orientações curriculares do município. Entretanto, um aspecto que diferencia esse caderno de outros é a restrição da abordagem da temática apenas aos relatos dos profissionais; não há, como em outros cadernos, uma retomada de produções da área, uma priorização de discussão teórico-conceitual ou orientações didáticas mais sistematizadas ao professor sobre a educação especial, o que leva a indagar: qual é a concepção de educação especial que sustenta essas orientações cur-

158 riculares? Discutindo sobre a estreita relação entre teoria e prática, no contexto do trabalho educativo no ensino superior, Saviani (2007, p. 108) chama a atenção para o fato de que a prática é a "razão de ser" da teoria, mas, em contrapartida, cabe "[...] a ela esclarecer a prática, tornando-a coerente, consistente, consequentemente eficaz".

Com relação às proposições curriculares para a educação especial identificadas nos documentos analisados, vale destacar o quanto são pontuais, fragmentadas e desarticuladas. Essa fragmentação observada nas propostas pedagógicas, também tem sido percebida em estudos produzidos na área da educação especial quanto à organização do trabalho pedagógico na escola. Analisando a inclusão de alunos com paralisia cerebral no ensino fundamental, Correia (2014) chama a atenção para a maneira fragmentada com que essa modalidade de ensino é compreendida por professores regentes, professores especializados e pedagogos, bem como para as práticas que se delineiam, fundamentadas nessas concepções. A ideia de que há um setor na escola para tratar do assunto (sala de recursos multifuncionais, com profissionais especializados), aliada ao desconhecimento de pedagogos e professores regentes acerca de como trabalhar com esses alunos, é utilizada como justificativa para 
a inexistência de uma prática pedagógica que integre e articule os diferentes espaços educativos. Como o aluno é integrante da educação especial, sobressai a visão de que ele é de responsabilidade dos profissionais especializados e tanto o ensino como a avaliação desse aluno devem ser feitos por eles. Assim, entende-se que a fragmentação, identificada nas propostas pedagógicas e/ou orientações curriculares, contribui para disseminar esse tipo de visão em relação à educação especial na escola.

Para que a criança se insira como participante da cultura, a natureza social do psiquismo humano - sua constituição social necessária - depende da qualidade das apropriações que faz das relações sociais orientadas e promovidas pela educação. Não é, portanto, de qualquer organização da educação infantil que se está falando. Nenhuma organização educativa prescinde de cuidadosa promoção de um projeto de humanização, como alerta Martins (2013) e com quem concordamos.

Garcia (2009) comenta que as proposições da "escola inclusiva" têm colocado para os sistemas municipais de ensino um conjunto de demandas para as quais há a necessidade de uma intensa mobilização de forma a rever e (re)organizar concepções e práticas. Em consonância com os documentos oficiais, a educação especial deve estruturar-se de maneira transversal aos níveis de ensino, integrar o projeto pedagógico da escola, articular-se com o ensino comum e atuar de forma a complementar e suplementar esse ensino.

A análise das orientações curriculares investigadas sugere que, na educação infantil, a educação especial tende a seguir rumos contrários a essa integração e articulação. Isso pode ser evidenciado na ausência da discussão sobre a área em parte das propostas; no apagamento da criança com deficiência, bem como na desconsideração das peculiaridades de seu desenvolvimento e de suas necessidades educacionais especiais; na desarticulação entre princípios que fundamentam a educação especial nessas propostas e nas orientações didáticas apresentadas. Essas constatações levam a concordar com as considerações de Garcia (2009, p. 136), quando afirma que: "[... ] a configuração que assume o trabalho pedagógico voltado aos sujeitos com deficiência mediante as políticas de inclusão escolar favorece a reposição do modelo tradicional de educação especial". 


\section{Considerações finais}

A investigação sobre como as Secretarias de Educação de municípios brasileiros incorporam em suas propostas curriculares para a educação infantil as orientações dos documentos oficiais na área da educação especial leva à constatação de que, de modo geral, há grandes lacunas em relação a essa modalidade de ensino nas propostas analisadas, seja devido à ausência dessa discussão, seja por conta de uma abordagem superficial e fragmentada do trabalho educativo com crianças que são público-alvo da educação especial. Essa ausência também pode ser observada em documentos produzidos no âmbito do MEC para a educação infantil, evidenciando que a necessidade de maior articulação entre educação infantil e educação especial também existe nas políticas em nível nacional.

Com este trabalho, constata-se a necessidade de ampliar a discussão sobre a educação especial na educação infantil, de forma a contribuir para o acúmulo e a solidificação de conhecimentos e proposições sobre como cuidar de bebês e crianças pequenas, que são público-alvo da educação especial nas instituições de educação infantil, e educá-las.

Muitos investimentos ainda são necessários para que, nos discursos que "veiculam sentidos e significados" sobre a educação especial na educação infantil e também nas práticas, os sistemas de ensino possam seguir, em suas propostas curriculares, um rumo que esteja em consonância com a efetivação de uma educação para todos.

\section{Notas}

1 Embora as Diretrizes Nacionais para a Educação Especial na Educação Básica (Resolução CNE/ CEB n 2/200 1) tratem também do aluno com altas habilidades e superdotação, neste trabalho, vamos enfocar mais especificamente as questões da criança com deficiência e transtornos globais do desenvolvimento.

2 Garcia (2009, p. 124) afirma que "[...] a análise documental tem sido uma forma facilitadora do acesso aos discursos políticos, os quais são veículos de sentidos e significados que contribuem na formação de concepções e na disseminação e incorporação de práticas".

3 Considerando o período em que as propostas pedagógicas ou curriculares analisadas foram elaboradas, neste estudo, não trataremos do Decreto no 7.611 , de 17 de novembro de 2011 , que dispõe sobre a educação especial e o atendimento educacional especializado, o qual revogou - Decreto n 6.571, de 17 de setembro de 2008, nem da Resolução n 4, de 2 de outubro de 2009, que institui as Diretrizes Operacionais para o Atendimento Educacional Especializado na Educação Básica, modalidade Educação Especial. 
Ivone Martins de Oliveira | Anna Maria Lunardi Padilha | Maria Flavia Silveira Barbosa

4 Esse aspecto já foi apontado por Garcia (2008), ao se reportar a interpretações da declaração produzida a partir da Convenção Interamericana para Eliminação de Todas as Formas de Discriminação contra Pessoas Portadoras de Deficiência, em 2009. Segundo a autora, dessas interpretações emerge uma associação entre os conceitos de "inclusão" e "acessibilidade".

5 No original: "Está en nuestras manos hacer que el niño ciego, sordo o débil mental no sean deficientes. Entonces desaparecerá también este concepto, signo inequívoco de nuestro proprio defecto" (VYGOTSKY, 1997, p. 82).

6 No original: "Nuestra existencia social determina nuestra consciencia" (VYGOTSKY, 1997, p. 179).

7 Este estudo se insere em um projeto de pesquisa mais amplo que tem como objetivo analisar a forma como Secretarias de Educação de capitais do País articulam, em suas propostas pedagógicas e/ou curriculares, as orientações curriculares para a creche e a pré-escola, estabelecidas pelo MEC, os conhecimentos produzidos na área educacional e as demandas locais colocadas pela educação infantil

8 Diferentemente das outras, a versão finalizada da Proposta Pedagógica 5 foi incorporada ao corpus desta pesquisa em agosto de 2013.

9 Tendo como base as referências, inferimos que a proposta foi publicada a partir de 2007.

10 Tendo como base as referências, inferimos que a proposta foi publicada a partir de 2011.

11 É importante ressaltar que o fato de, em alguns casos, termos identificado referências esporádicas e pontuais à educação especial para as crianças da educação infantil não significa, necessariamente, a não existência de documentos nesses municípios. Neste trabalho, procuramos nos restringir às orientações curriculares publicizadas nos sítios das Secretarias de Educação no mês de janeiro de 2013.

12 No original: "La ceguera en sí no hace al niño deficiente, no es una defectividad, es decir, una deficiencia, una carencia, una enfermedad. Llega a serlo sólo en ciertas condiciones sociales de existencia del ciego" (VYGOTSKY, 1997, p. 83).

\section{Referências}

BRASIL. Lei n 9.394, de 20 de dezembro de 1996. Estabelece as diretrizes e bases da educação nacional. Diário Oficial [da] República Federativa do Brasil, Poder Executivo, Brasília, DF, 23 dez. 1996. Seção 1, p. 27833.

Resolução CNE/CEB n ${ }^{\circ} \mathbf{1}$, de 7 de abril de 1999. Estabelece as Diretrizes Curriculares Nacionais para a Educação Infantil. Brasília, DF. Disponível em: <http:// portal.mec.gov.br/cne/arquivos/pdf/CEBO 199.pdf>. Acesso em: 7 jun. 2016.

Parecer CNE/CEB $\mathbf{n}^{\circ}$ 17, de 3 de julho de 2001, que trata das Diretrizes Nacionais para a Educação Especial na Educação Básica. Brasília, 2001 . Disponível em: <http:/ / portal.mec.gov.br/index.php?id= 13251 : parecer-ceb-200 1 \&option=com_content>. Acesso em: 14 dez. 2014. 
A educação especial em propostas curriculares para a educação infantil

Resolução CNE/CEB n 2 2, de 11 de setembro de 2001. Brasilia, DF. Estabelece as Diretrizes Nacionais para a Educação Especial na Educação Básica. Disponível em:<http://siau.edunet.sp.gov.br/ItemLise/arquivos/notas/RESCNECEBO2_01.HTM>. Acesso em: 13 jan. 2014.

Decreto n. 6.571, de 17 de setembro de 2008. Disponível em <http://www. planalto.gov.br/ccivil_03/_Ato2007-2010/2008/Decreto/D6571.htm>. Acesso em: 7 jun. 2016.

Resolução CNE/CEB n ${ }^{\circ}$ 4, de 2 de outubro de 2009. Disponível em:<http://portal.mec.gov.br/dmdocuments/rceb004_09.pdf>. Acesso em: 7 jun. 2016.

Decreto $\mathbf{n}^{\circ}$ 7.611, de 17 de novembro de 2011. Disponível em: <http://www. planalto.gov.br/ccivil_03/_ato2011-2014/2011/decreto/d7611.htm>. Acesso em: 7 jun. 2016.

Política Nacional de Educação Especial na Perspectiva da Educação Inclusiva, de 7 de janeiro de 2008. Brasília: Ministério da Educação/Secretaria de Educação Especial, 2014.

Decreto n $^{\circ}$ 6.949, de 25 de agosto de 2009. Trata da Convenção Internacional sobre os Direitos da Pessoa com Deficiência e seu Protocolo Facultativo, assinados em 162 New York, em março de 2007. Disponível em:<https://www.planalto.gov.br/ccivil_03/_ ato2007-2010/2009/decreto/d6949.htm>. Acesso em: 13 dez. 2014.

Resolução CNE/CEB n 5, de 17 de dezembro de 2009. Estabelece as Diretrizes Curriculares Nacionais para a Educação Infantil. Brasília, DF. Disponível em:<http://portal. mec.gov.br/index.php?id=1 3684: resolucoes-ceb-2009\&option=com_content>. Acesso em: 14 dez. 2014.

Projeto Educação Infantil 100\% inclusiva: acesso, permanência e qualidade. Brasília: Ministério da Educação/Secretaria de Educação Continuada, Alfabetização, Diversidade e Inclusão, 2014.

CAIADO, Kátia Regina Moreno; LAPLANE, Adriana Lia Friszman. Tramas e redes na construção de uma política municipal de educação inclusiva. In: BAPTISTA, Cláudio Roberto; JESUS, Denise Meyrelles (Org.). Avanços em políticas de inclusão: o contexto da educação especial no Brasil e em outros países. Porto Alegre: Mediação, 2009.

CORREIA, Vasti Gonçalves de Paula. A inclusão escolar de alunos com paralisia cerebral sem fala articulada: discussões sobre linguagem, comunicação alternativa e processos comunicativos. 2014. 282f. Tese (Doutorado em Educação) - Programa de Pós-Graduação em Educação, Universidade Federal do Espírito Santo, Vitória, 2014. 
COTONHOTO, Larissy Alves. Currículo e atendimento educacional especializado na educação infantil: possibilidades e desafios à inclusão escolar. 2014. 264f. Tese (Doutorado em Educação) - Programa de Pós-Graduação em Educação, Universidade Federal do Espírito Santo, Vitória, 2014.

IBGE. Instituto Nacional de Estudos e Pesquisas Educacionais Anísio Teixeira. Resultados finais do censo escolar 2012. Disponível em: <http://portal.inep.gov.br/basica-censo-escolar-matricula>. Acesso em: 2 ago. 2013.

Instituto Nacional de Estudos e Pesquisas Educacionais Anísio Teixeira. Cidades. Disponível em: <http://www.ibge.gov.br/home>. Acesso em: 1 ago. 2013.

GARCIA, Rosalba Maria Cardoso. Políticas inclusivas na educação: do global ao local. In: BAPTISTA, Cláudio Roberto; CAIADO, Kátia Regina Moreno; JESUS, Denise Meyrelles (Org.). Educação especial: diálogo e pluralidade. Porto Alegre: Mediação, 2008.

Política de educação inclusiva e trabalho pedagógico: uma análise do modelo de educação especial na educação básica. In: BAPTISTA, Cláudio Roberto; JESUS, Denise Meyrelles (Org.). Avanços em políticas de inclusão: o contexto da educação especial no Brasil e em outros países. Porto Alegre: Mediação, 2009.

GARCIA, Rosalba Maria Cardoso; LOPEZ, Graziela Maria Beretta. Políticas de educação inclusiva no Brasil: uma análise da educação especial na educação infantil (2000-2010). In: REUNIÃO ANUAL DA ASSOCIAÇÃO NACIONAL DE PÓS-GRADUAÇÃO E PESQUISA EM EDUCAÇÃO, 34; 201 1, Natal. Anais... Natal: Anped, 2011.

MARTINS, Lígia Márcia. O desenvolvimento do psiquismo e a educação escolar: contribuições à luz da psicologia histórico-cultural e da pedagogia histórico-crítica. Campinas: Autores Associados, 2013.

NUNES, Maria Fernandes Rezende; CORSINO, Patrícia; DIDONET, Vital. Educação infantil no Brasil: primeira etapa da educação básica. Brasília: Unesco/Ministério da Educação/ Secretaria de Educação Básica, Fundação Orsa, 2011.

OLIVEIRA, Cristina Borges. Infância e deficiência no Brasil: uma história de ocultação e silenciamento. Arquivos Analíticos de Políticas Educativas, Tempe (Arizona, United States), v. 19, n. 26, p. 1-19, jun. 2011.

PASQUALINI, Juliana Campregher. A educação escolar da criança pequena na perspectiva histórico-cultural e histórico-crítica. In: MARSIGLIA, Ana Carolina Galvão (Org.). Pedagogia histórico-crítica: 30 anos. Campinas: Autores Associados, 2012.

SACRISTAN, Gimeno. O currículo: uma reflexão sobre a prática. Tradução Ernani da Fonseca Rosa. Porto Alegre: Artmed, 2000. 
A educação especial em propostas curriculares para a educação infantil

SAVIANI, Dermeval. Pedagogia histórico-crítica: primeiras aproximações. 8. ed. Campinas: Autores Associados, 2003.

Pedagogia: o espaço da educação na universidade. Cadernos de Pesquisa, São Paulo, v. 37, n 130, p. 99-134,jan./abr. 2007.

VIGOTSKY, Lev. Manuscrito de 1929. Educação \& Sociedade, Campinas, v. 21 , n. 71 , p. 21-44, julho, 2000.

Fundamentos de defectología. Tradução Julio Guillermo Blank. Madrid: Visor, 1997. (Obras Escogidas, v. 5.).

WIGGERS, Verena. Aportes teóricos e metodológicos que subsidiam as orientações curriculares na educação infantil. In: REUNIÃO ANUAL DA ASSOCIAÇÃO NACIONAL DE PÓS-GRADUAÇÃO E PESQUISA EM EDUCAÇÃO, 33; 2009, Caxambu. Anais. Caxambu: Anped, 2009.

Profa. Dra. Ivone Martins de Oliveira

Universidade Federal do Espírito Santo

Centro de Educação

Programa de Pós-Graduação em Educação

164 Grupo de Pesquisa Desenvolvimento Humano e Práticas Educativas em espaços escolares e não escolares

E-mail | ivone.mo@terra.com.br

Profa. Dra. Anna Maria Lunardi Padilha Universidade Metodista de Piracicaba Faculdade de Ciências Humanas

Programa de Pós-Graduação em Educação

Grupo de Pesquisa Desenvolvimento Humano e Práticas Educativas em espaços escolares e não escolares E-mail | anapadi@terra.com.br

Profa. Dra. Maria Flavia Silveira Barbosa Universidade Federal de Uberlândia Instituto de Artes

Programa de Pós-Graduação em Música 
Grupo de Pesquisa Desenvolvimento Humano e Práticas Educativas em espaços escolares e não escolares

E-mail |mfsb65@yahoo.com

Recebido 6 jun. 2015

Aceito 3 nov 2015 